\title{
СОВРЕМЕННОЕ СОСТОЯНИЕ И ПЕРСПЕКТИВЫ РАЗВИТИЯ АКВАКУЛЬТУРЫ: ФЕДЕРАЛЬНЫЙ И РЕГИОНАЛЬНЫЙ АСПЕКТЫ
}

\author{
DOI: 10.32620/cher.2018.4.02
}

Постановка проблемы. В статье анализируются проблемы и современные тенденции функционирования аквакультуры, а также определяются перспективы ее развития в обозримой перспективе. Предметом исследования является оценка современного состояния и развития аквакультуры на федеральном и региональном уровне. Целью статьи является анализ современного состояния и основных проблем, связанных с функционированием аквакультуры в экономике. Объект исследования - стратегии развития аквакультуры, основанном на выявлении важнейших социально-экономических тенденций. Meтодbl, использованные в исследовании - научный, логический, ретроспективный. Гипотеза исследования - целесообразность развития различных направлений аквакультуры: пастбищная аквакультура; прудовая аквакультура; индустриальная аквакультура; марикультура; рекреационная аквакультура. Изложение основного материала. Ведущее место в аквакультуре занимают карповые виды рыб, годовое производство которых составляет более 80 \%. Существует тенденция расширения видового разнообразия выращиваемых рыб как за счет аборигенной ихтиофауны, так и за счет использования ранее акклиматизированных видов. Определенное развитие получило фермерское рыбоводство, однако учет выращиваемой рыбы в этом секторе аквакультуры в настоящее время затруднен и оценивается экспертным путем. Оригинальность и практическое значение исследования. Основными направлениями практической деятельности являются: создания правовой базы функционирования предприятий аквакультуры различных форм собственности; широкомасштабное строительство воспроизводственных комплексов на крупных естественных водоемах и водохранилищах; подготовка и переподготовка кадров различного управленческого уровня. Выводы исследования. Формирование регионального механизма развития аквакультуры, объединяющего экономические интересы государства и крупного региона в лице органов власти, кредитных учреждений, предприятий рыбного комплекса, а также представителей малого и среднего бизнеса должно привести к реализации общегосударственной политики в нескольких смежных отраслях и направлениях народного хозяйства.

Ключевые слова:

Аквакультура, развитие, фермы, формы собственности, экономические, социальные интересы.

\section{MODERN CONDITION AND PERSPECTIVES OF DEVELOPMENT OF AQUACULTURE: FEDERAL AND REGIONAL ASPECTS}

Formulation of the problem. The article analyzes the problems and current trends in the functioning of aquaculture, and also determines the prospects for its development in the foreseeable future. The subject of the research is the assessment of the current state and development of aquaculture at the federal and regional levels.

${ }^{1}$ Павлов Костянтин Вікторович, д-р екон. наук, професор кафедри «Економіка та управління», Іжевська філія Росийського університету кооперації, м. Іжевськ, Удмуртія, Росія.

Pavlov Konstantin, Professor, Ph.D. in Economics, professor of Economy and management Department of the Izhevsk branch the Russian university of cooperation, Izhevsk, Udmurtia, Russia.

ORCID ID: 0000-0001-7837-6209

e-mail: kvp_ruk@mail.ru

${ }^{2}$ Андріїва Ірина Григорівна, канд. екон. наук, доц., зав. кафедри «Економічна теорія та економіка АПК», Белгородський державний аграрний університет ім. В. Я. Горина, м. Белгород, Росія.

Andreeva Iryna, Ph.D. in Economics, associate professor, Head of Economic Theory and Economics of Agroindustrial Complex Department, Belgorod State Agrarian University named V. Gorina, Belgorod, Russia.

ORCID ID: 0000-0000-2317-2350

e-mail: info@bsaa.edu.ru

${ }^{3}$ Метслєва Марина Генадіївна, канд. ветер. наук, доцент кафедри «Економіка та управління», Іжевська філія Росийського університету кооперації, м. Іжевськ, Удмуртія, Росія.

Meteleva Marina, Ph.D. in Veterinary, associate professor of Economic Theory and Economics of Agroindustrial Complex Department, Belgorod State Agrarian University named V. Gorina, Belgorod, Russia.

ORCID ID: 0000-0000-8337-7243

e-mail: info@bsaa.edu.ru 
The aim of the research is to analyze the current state and the main problems associated with the functioning of aquaculture in the economy. The object of the research is aquaculture development strategies based on identifying the most important socio-economic trends. The methods used of the research - scientific, logical, retrospective. The hypothesis of the research - the feasibility of the development of various areas of aquaculture: pasture aquaculture; pond aquaculture; industrial aquaculture; mariculture; recreational aquaculture. The statement of basic materials. The carp species of fish occupy the leading place in aquaculture; their annual production is more than $80 \%$. There is a tendency to expand the species diversity of farmed fish through both the aboriginal ichthyofauna and the use of previously acclimatized species. Farmer fish farming has received some development, however, accounting for farmed fish in this sector of aquaculture is currently difficult and is estimated by expert means. Originality and practical significance of the research. The main areas of practical activity are: the creation of a legal framework for the functioning of aquaculture enterprises of various forms of ownership; largescale construction of reproduction complexes in large natural water bodies and reservoirs; training and retraining of personnel at various managerial levels. Conclusions of the research. The formation of a regional mechanism for the development of aquaculture, which unites the economic interests of the state and a large region represented by the authorities, credit institutions, enterprises of the fish complex, as well as representatives of small and medium-sized businesses should lead to the implementation of national policy in several related sectors and areas of the national economy.

Key words:

aquaculture, development, farms, forms of ownership, economic, social interests.

\section{СУЧАСНИЙ СТАН І ПЕРСПЕКТИВИ РОЗВИТКУ АКВАКУЛЬТУРИ: ФЕДЕРАЛЬНИЙ І РЕГІОНАЛЬНИЙ АСПЕКТИ}

Постановка проблеми. У статті аналізуються проблеми і сучасні тенденції функціонування аквакультури, а також визначаються перспективи її розвитку в доступній для огляду перспективі. Предметом дослідження є оцінка сучасного стану та розвитку аквакультури на федеральному і регіональному рівні. Метою статті є аналіз сучасного стану та основних проблем, пов'язаних з функціонуванням аквакультури в економіці. Об'єкт дослідження - стратегії розвитку аквакультури, заснованому на виявленні найважливіших соціально-економічних тенденцій. Методи, використані $в$ дослідженні - науковий, логічний, ретроспективний. Гіпотеза дослідження - доцільність розвитку різних напрямків аквакультури: пасовищна аквакультура; ставкова аквакультура; індустріальна аквакультура; марикультура; рекреаційна аквакультура. Виклад основного матеріалу. Провідне місце в аквакультурі займають коропові види риб, річне виробництво яких становить понад $80 \%$. Існує тенденція розширення видового різноманіття вирощуваних риб як за рахунок аборигенної іхтіофауни, так і за рахунок використання раніше акліматизованих видів. Певний розвиток отримало фермерське рибництво, однак облік вирощуваної риби в цьому секторі аквакультури в даний час утруднений $\mathrm{i}$ оцінюється експертним шляхом. Оригінальність $і$ практичне значення дослідження. Основними напрямками практичної діяльності є: створення правової бази функціонування підприємств аквакультури різних форм власності; широкомасштабне будівництво відтворювальних комплексів на великих природних водоймах і водосховищах; підготовка і перепідготовка кадрів різного управлінського рівня. Висновки дослідження. Формування регіонального механізму розвитку аквакультури, що об'єднує економічні інтереси держави і великого регіону в особі органів влади, кредитних установ, підприємств рибного комплексу, а також представників малого та середнього бізнесу має привести до реалізації загальнодержавної політики в декількох суміжних галузях і напрямках народного господарства.

\section{Ключові слова:}

аквакультура, розвиток, ферми, форми власності, економічні, соціальні інтереси.

Постановка проблемы. До последнего времени развитию рыбоводства в России отводилась второстепенная роль источника местного пищевого сырья, что определило слабое развитие современной отечественной аквакультуры, не соответствующее ее потенциальным возможностям и не способное удовлетворять возрастающие потребности населения в высококачественных рыбных продуктах.

Рыбохозяйственный фонд внутренних пресноводных водоемов России включает 22,5 млн. га озер, 4,3 млн. га водохранилищ, 0,96 млн. га сельскохозяйственных водоемов комплексного назначения, 142,9 тыс. га прудов и 523 тыс. км рек. Наибольшим фондом рыбохозяйственных водоемов располагают Сибирский (7516,6 тыс. га), Северо-Западный $(6510,4)$ и Уральский $(6270,4)$ федеральные округа. Исходя из общей площади рыбохозяйственных водоемов и народонаселения России, обеспеченность каждого жителя 
страны водоемами, пригодными для развития аквакультуры, составляет 0,19 га на человека. В Дальневосточном федеральном округе этот показатель составляет 0,65 га, в СевероЗападном - 0,46 га, а в Центральном - только 0,02 га.

Общий фонд прудовых площадей, находящихся на балансе рыбохозяйственных предприятий и организаций по состоянию на 01.01.2016, составлял 142,9 тыс. га, однако для выращивания рыбы используется не более 110 тыс. га прудов. В водоемах Российской Федерации обитает 295 типично пресноводных видов рыб, относящихся к 140 родам, 34 семействам и 13 отрядам. В промысловых уловах в реках, озерах и водохранилищах отмечаются представители 87 видов рыб. Объектами искусственного разведения в пресных водах России являются представители 48 видов рыб, 3 вида ракообразных, а также 12 видов морских гидробионтов. В промышленном рыбоводстве России в настоящее время культивируется 29 пород, кроссов и типов, а также 9 одомашненных форм карповых, лососевых, осетровых, сиговых и цихлидовых рыб. Ремонтно-маточное поголовье племенных рыб различных пород в количестве более 100 тыс. голов выращивается в 25 племенных рыбоводных хозяйствах-оригинаторах.

Ведущее место в отечественной аквакультуре занимают карповые виды рыб, годовое производство которых в последние годы составляет более 80 процентов. Наметилась тенденция расширения видового разнообразия выращиваемых рыб как за счет аборигенной ихтиофауны (линь, сом обыкновенный, карась), так и за счет использования ранее акклиматизированных видов: буффало, канальный сом, пиленгас. В промышленных объемах начали разводить ракообразных речного рака и пресноводную креветку.

Анализ последних исследований и публикаций. В Дальневосточном, Северном и Черноморском бассейнах получило развитие выращивание в опытнопроизводственном режиме таких ценных объектов морской аквакультуры, как мидии, трепанги, кефаль, треска, камбала-калкан и другие. Объектами искусственного воспроизводства на предприятиях аквакультуры являются 15 видов и подвидов рыб, занесенных в Красную книгу Российской Федерации.

Выращиванием рыбы и других объектов аквакультуры в Российской Федерации в последние 10 лет занимаются предприятия различных форм собственности (государственной, кооперативной, частной). Основной объем товарной рыбы в России производят предприятия различных форм собственности, входящие в состав ассоциации «Государственно-кооперативное объединение рыбного хозяйства (Росрыбхоз)» и рыбоводные хозяйства сельскохозяйственного профиля. В составе ГКО «Росрыбхоз» в настоящее время работает около 500 предприятий аквакультуры. Определенное развитие получило фермерское рыбоводство, однако учет выращиваемой рыбы в этом секторе аквакультуры в настоящее время затруднен и оценивается экспертным путем. На рыбоводных предприятиях России государственной и других форм собственности работает более 22 тыс. человек, а в фермерских хозяйствах - около 5 тыс. человек.

В рыбном хозяйстве страны сохраняются механизмы и условия хозяйствования, характерные для неразвитой рыночной экономики, в которой действует ряд факторов, негативно влияющих на функционирование и развитие рыбохозяйственного комплекса, включая аквакультуру.

Современные авторы к основным факторам, сдерживающими развитие аквакультуры в нашей стране, относят:

- отсутствие законодательства, учитывающего в полной мере специфику функционирования аквакультуры;

- слабо развитая рыночная инфраструктура и отсутствие маркетинговой информации о состоянии российского и международного рынков рыбопродукции и аквакультуры;

- высокая степень износа основных производственных фондов;

- прекращение ввода новых производственных мощностей;

- дефицит инвестиционных ресурсов из-за низкой инвестиционной привлекательности существующих рыбоводных хозяйств [4].

В марте 2013 года распоряжением правительства РФ была утверждена государственная программа «Развитие рыбохозяйственного комплекса», при реализации ее базового сценария объем добычи водных биоресурсов к 2020 г. должен составить 4,5 млн. т., объем производства продукции аквакультуры - 150 тыс. т. Производство рыбы, а также переработанных и консервированных рыбных продуктов должно достичь 3,9 млн. т., среднедушевое потребление рыбы и рыбопродук- 
тов населением РФ - 22,7 кг в год, доля отечественной пищевой рыбной продукции на внутреннем рынке - 68,2\%, прирост производительности труда (к уровню 2013 г.) - 37\%. С 1 января 2014 года вступил в силу федеральный закон «Об аквакультуре (рыбоводстве)». В законе отражены такие важные положения, как отнесение товарной аквакультуры (товарного рыбоводства) к сельскохозяйственному производству, закрепление права собственности на объекты аквакультуры [2]. Аквакультура (от лат. aqua - вода и cultura возделывание, уход) - это разведение и выращивание водных организмов (рыб, моллюсков, ракообразных, водорослей) в контролируемых условиях для повышения продуктивности водоемов [11].

Основными факторами, определяющими необходимость развития аквакультуры России, являются:

- повышение спроса на продукцию аквакультуры внутри страны в условиях современных тенденций сокращения промысла в морях и океанах;

- необходимость восстановления нормативного потребления рыбы и рыбных продуктов жителями России;

- повышение жизненного уровня и улучшение рациона питания населения;

- формирование благоприятного инвестиционного климата с учетом совершенствования налогового, ценового и таможенного регулирования;

- повышение доходов и улучшение рациона питания населения.

Несмотря на обнадеживающие прогнозы, остаются проблемы технологического и организационного характера, которые могут лимитировать ожидающийся рост увеличения объемов аквакультуры в мире.

К технологическим ограничениям относятся:

- болезни культивируемых объектов, наиболее серьезно влияющие на производство и торговлю продукцией аквакультуры. Несмотря на то, что большинство бактериальных и вирусных инфекций не представляют прямой угрозы здоровью человека, они отрицательно влияют на продуктивность, реализуемость товара и общественное мнение. Распространению болезней способствует перенос патогенного начала из-за расширяющейся торговли живыми гидробионтами и продукцией из них; усиливающаяся конкуренция с животноводством и птицеводством в использовании комбикормов, рецептура и технологии изготовления которых для гидробионтов значительно сложнее и дороже, что соответственно приведет к удорожанию продукции аквакультуры, а также экологические проблемы, связанные с качеством среды выращивания гидробионтов, большая часть которых сосредоточена в прибрежных водах и пресноводных водоемах, чаще подверженных антропогенному загрязнению [6].

Целью статьи является анализ современного состояния и основных проблем, связанных с функционированием аквакультуры в российской экономике, в том числе в некоторых центральных регионах страны, а также с определением стратегии развития аквакультуры в обозримой перспективе, основанном на выявлении важнейших социальноэкономических тенденций.

Изложение основного материала исследования. Кроме того, все более жесткое следование общемировым стандартам и правилам производства и реализации пищевой продукции, в том числе и аквакультуры, с одной стороны, снижает потенциальную опасность аквакультуры, улучшает качество продукта и способствует повышению доверия потребителя, а с другой - значительно усложняет технологические процессы и ограничивает объемы реализации, особенно на мировых рынках.

В долгосрочном периоде (до 2020 года) отечественная аквакультура должна развиваться на инновационной основе с эффективным использованием российских и зарубежных научно-технических разработок и передового опыта. Приоритетным направлением в этом периоде является пастбищная аквакультура, на развитие которой практически не оказывают влияния несколько факторов, серьезно лимитирующих функционирование прудового и индустриального рыбоводства: не требуется больших капиталовложений, земельных площадей, водопотребления и огромных затрат искусственных комбикормов.

Развитие пойдет за счет массового вселения растительноядных рыб в крупные водоемы центральных и южных регионов страны, а также лососевых и сиговых рыб в водоемы северных зон России. Внедрение в северную аквакультуру современных технологий выращивания сиговых видов рыб позволит 
получить высококачественную рыбопродукцию в объеме 20 тыс. т. Особую роль в развитии отечественной аквакультуры будет играть фермерское рыбоводство, основными производственными мощностями которого служат пруды, малые водохранилища и небольшие озера, общая площадь которых в России превышает 1 млн. га.

Широкомасштабное использование в фермерском хозяйстве разработанного в России комплекса интегрированных технологий совместного выращивания рыбы с другими видами сельскохозяйственных животных и растений обеспечит производство рыбы в хозяйствах этого типа в объеме до 30 тыс. т. При этом существование фермерских хозяйств окажет благоприятное влияние на продуктивность водных и земельных угодий в составе агрогидробиоценозов, решатся важные задачи социально-экономического развития сельских территорий.

В прудовом рыбоводстве интенсификация производства будет осуществляться за счет широкомасштабного внедрения высокопродуктивных пород и расширения видового состава рыб - объектов товарного рыбоводства, позволяющих в ресурсосберегающем режиме максимально использовать продукционные возможности прудов. Средняя рыбопродуктивность прудов составит 20 ц/га, что без ввода новых прудовых площадей позволит довести объем производства прудовой рыбы до 215 тыс. т.

Аквакультура в мире продолжает расширяться, становится более разнообразной, интенсивной и технологически совершенной. В настоящее время аквакультура рассматривается не только как деятельность, удовлетворяющая нужды производителей продуктов питания, но и как одно из средств экономического роста и достижения разнообразных социальных и экологических целей. Осознание необходимости ускоренного развития аквакультуры ведет к принятию соответствующих законов и стратегий, регулирующих ее деятельность [9]. Аквакультура является важнейшим направлением функционирования агропромышленного, рыбохозяйственного и природоохранного комплексов Российской Федерации, обеспечивающих продовольственную безопасность страны.

Базируясь на комплексном использовании природно-ресурсного и социального потенциала страны, деятельность аквакультуры направлена на решение следующих важнейших общегосударственных задач:

- обеспечение населения продуктами питания животного происхождения;

- увеличение трудозанятости населения, особенно в сельской местности и прибрежных территориях;

- снижение импортозависимости в поставках продовольствия;

- сохранение запасов водных биологических ресурсов и биоразнообразия водных животных и растений в естественной среде обитания [12].

При положительном решении указанных задач аквакультура будет способствовать социально-экономическому развитию регионов России. Развитие аквакультуры, предусматривающей широкий спектр производства гидробионтов, их переработку и хранение, будет способствовать обеспечению высокой трудозанятости населения, в том числе за счет развития смежных отраслей, повышению доходности семей и, как следствие, улучшению здоровья и качества жизни населения России.

Белгородская область - активный участник программы развития сельского хозяйства. В регионе ещё в 2013 году была принята областная программа «Развитие аквакультуры ценных пород рыб и других гидробионтов в Белгородской области на 2013-2015 годы и на период до 2020 года». Объем финансирования программы - более 2 млрд. рублей [1].

Эффективность отрасли во многом будет определяться стратегией её развития, поэтому в работе отражен анализ существующих стратегий развития рыбоводческих предприятий отрасли, а ее целью являлась выработка рекомендаций по их совершенствованию. Регион занимает 22 место в РФ по производству рыбы и 1 место в ЦФО по производству свежей и охлажденной рыбы на основе аквакультуры (таблица 1).

Многочисленные пруды широко используются для выращивания и воспроизводства рыбы. Среднее потребление на душу населения - 13 кг в год, из них 3,1-3,5 кг - местного производства. В области организованы рыбхозы, которые выращивают зеркального карпа, толстолобика, белого амура, бестера. Осваивается производство ценных пород рыбы (форель, осетр), ведутся работы по воспроизводству видов рыбы, занесенных в Красную книгу региона (линь, язь). В Белгородской области одобрен Правительством регио- 
на и реализуется проект «Строительство завода по производству комбикормов для ценных пород рыб», в регионе предполагается строительство новых производств на основе использования самых современных технологий. В течение первого этапа реализации про- граммы развития отрасли необходимо решить несколько принципиальных вопросов, обеспечивающих создание хорошей материально-технической и кадровой базы для успешного достижения целевых показателей 2020 года.

Т а б л и ц а 1

Показатели развития аквакультуры в субъектах Центрального федерального округа России, 2016г., в тоннах

\begin{tabular}{|l|c|c|}
\hline $\begin{array}{c}\text { Наименование субъекта } \\
\text { Российской Федерации }\end{array}$ & $\begin{array}{c}\text { Производство (выращивание) } \\
\text { рыбопосадочного материала }\end{array}$ & $\begin{array}{c}\text { Производство (выращивание) товарной } \\
\text { рыбы и других объектов промышленно- } \\
\text { го рыбоводства по категориям хозяйств }\end{array}$ \\
\hline Российская Федерация & 30602 & 155355 \\
\hline Центральный федеральный & 8953 & 5975 \\
\hline Белгородская область & 2041 & 450 \\
\hline Брянская область & 198 & 298 \\
\hline Владимирская область & 101 & 3962 \\
\hline Воронежская область & 443 & 580 \\
\hline Ивановская область & 8 & 417 \\
\hline Калужская область & 228 & 1660 \\
\hline Костромская область & 117 & 2600 \\
\hline Курская область & 560 & 3621 \\
\hline Липецкая область & 1470 & 185 \\
\hline Московская область & 1078 & 2160 \\
\hline Орловская область & 0 & 379 \\
\hline Рязанская область & 912 & 951 \\
\hline Смоленская область & 88 & 394 \\
\hline Тамбовская область & 147 & 740 \\
\hline Тверская область & 232 & 398 \\
\hline Тульская область & 1330 & \\
\hline
\end{tabular}

Источник: разработано авторами

Основными направлениями деятельности являются:

- завершение создания правовой и законодательной базы функционирования предприятий аквакультуры различных форм собственности;

- широкомасштабное строительство воспроизводственных комплексов на крупных естественных водоемах и водохранилищах;

- подготовка и переподготовка кадров различного управленческого уровня;

- протекционистская государственная политика, направленная на поддержку развития аквакультуры в стране.

Белгородская область входит в Центральный федеральный округ, который является наиболее населенным и располагает наименьшим рыбохозяйственным фондом озер и водохранилищ, в связи с чем приори- тетными направлениями развития аквакультуры являются прудовое рыбоводство и индустриальная аквакультура с использованием подогретых вод энергетических объектов. Высокая стоимость земли, воды и значительный спрос на высокоценные рыбные продукты позволяет прогнозировать выращивание деликатесных видов и пород рыб в индустриальных установках с замкнутым циклом водообеспечения.

Например, на территории Белгородской области началась реализация проекта «Строительство рыбоводного хозяйства по выращиванию клариевого сома в установках замкнутого водоснабжения в Белгородском районе». В планах у владельцев будущего рыбного хозяйства - создание рыбоводного хозяйства с обслуживающей инфраструктурой. Объём инвестиций в проект составит свыше 29 миллионов рублей. После выхода 
рыбоводного хозяйства на проектную мощность в регионе ежегодно планируют производить 150 тонн клариевого сома, что позволит обеспечить население Белгородской области и близлежащих регионов экологически чистой продукцией ценных пород рыб [5]. Африканский клариевый сом (или мраморный нильский клариас) - традиционный объект тепловодной аквакультуры в африканских странах, которого сегодня активно разводят по всему миру. Около 20 лет назад в рамках программы обеспечения продовольствием населения африканских стран он был впервые завезён в Голландию из Африки [10]. Во многом из-за быстрой окупаемости (1,5 - 2 года, тогда как форели - 7-8 лет) эту ценную породу рыб всё активнее используют рыбоводные хозяйства России.

Белгородский регион имеет объективный потенциал для увеличения производства рыбы через развитие современных производительных систем аквакультуры, диверсификации ассортимента выращиваемых видов рыб, расширения услуг в отрасли и других видов деятельности при финансовой поддержке и в условиях осуществления новых исследований.

В долгосрочном периоде (до 2020 года) отечественная аквакультура должна развиваться на инновационной основе с эффективным использованием российских и зарубежных научно-технических разработок и передового опыта [3]. Если по России в целом приоритетным направлением в этом периоде будет является пастбищная аквакультура, то в Белгородской области - прудовое и индустриальное рыбоводство. При этом необходимо помнить, что данные направления несут с собой много затрат: для них требуются большие капиталовложения, земельные площади, водопотребление и затраты на комбикорма.

Выводы и перспективы дальнейших исследований. Особую роль в развитии отечественной аквакультуры будет играть фермерское рыбоводство, основными производственными мощностями которого послужат пруды и малые водохранилища. Широкомасштабное использование в фермерском хозяйстве комплекса интегрированных технологий совместного выращивания рыбы с другими видами сельскохозяйственных животных и растений обеспечит производство рыбы в хозяйствах этого типа в объемах, достаточных для насыщения внутреннего регионального рынка. При этом существование фермерских хозяйств окажет благоприятное влияние на продуктивность водных и земельных угодий в составе агрогидробиоценозов, решатся важные задачи социальноэкономического развития сельских территорий.

В прудовом рыбоводстве интенсификация производства будет осуществляться за счет широкомасштабного внедрения высокопродуктивных пород и расширения видового состава рыб - объектов товарного рыбоводства, позволяющих в ресурсосберегающем режиме максимально использовать продукционные возможности прудов [7]. Средняя рыбопродуктивность прудов должна достичь показателя в 20 ц/га.

Улучшение условий жизни и повышение уровня доходов населения Белгородской области повысит спрос на ценные виды рыб, что будет стимулировать развитие индустриального рыбоводства. За счет массового применения отечественных научно-технических разработок, базирующихся на интенсивных методах выращивания лососевых, осетровых и других ценных видов рыб, в условиях садковых и бассейновых хозяйств, а также индустриальных установок с замкнутым циклом водообеспечения можно обеспечить рынок деликатесной продукцией высоких потребительских качеств. Если регион сохранит имеющиеся темпы развития, то к 2020 году объемы производства продукции аквакультуры могут вырасти в 4 раза по отношению к настоящему времени.

\section{Литература}

1. Государственная программа "Развитие сельского хозяйства и рыбоводства в Белгородской области на 2014-2020 годы"/ в ред. постановлений Правительства Белгородской области от 24.02.2014 № 55-пп, от 30.06.2014 № 235-пП, от 15.07.2014 № 258.

2. Ф3 Российской Федерации от 2 июля 2013 г. № 148-Ф3 "Об аквакультуре (рыбоводстве) и о внесении изменений в отдельные законодательные акты Российской Федерации". [Электронный ресурс]. - Режим доступа: http://www.rg.ru/

3. Стратегия развития аквакультуры в Российской Федерации на период до 2020 года. [Электронный ресурс]. - Режим доступа: http://www.mcx.ru/

4. Обзор аквакультуры России и мира 2017 г., Информационно-аналитическая 
служба ОАО «Корпорация «Развитие». - Белгород: «Развитие», 2018. - 73 с.

5. Кулаченко В. П. Биологические показатели и пищевая ценность видов рыб в аквакультуре Белгородской области / В. П. Кулаченко, И. В. Кулаченко, Ю. Н. Литвинов // Вестник Курской государственной сельскохозяйственной академии. - 2011. - № 1. - С. 53-55.

6. Зикова Н. В. Исследование тенденций, закономерностей, факторов и условий развития аквакультуры в системе устойчивого функционирования экономики региона / $\mathrm{H}$. В. Зикова // Российское предпринимательство. - 2010. - № 12 Вып. 2 (174). - С. 183-188.

7. Хмыров А. В. Проект «Воспроизводство видов рыб, занесенных в Красную книгу Белгородской области» / А. В. Хмыров // Белгородский агромир. - 2010. - № 6. - С. 28-29.

8. Fish farms to produce nearly two thirds of global food fish supply by 2030 . Retrieved from: http://www.fao.org

9. Hillary S. Egna Boyd Dynamics of Pond Aquaculture Hillary S. Egna, Claude E. // CRC Press, 1997. Retrieved from: http://insightmaker.com /

10. Joint FAO/NACA/WHO Study Group Food safety issues associated with products from aquaculture. World Health Organization Technical Report Series № 883. 1999. Retrieved from: http://www.who.int /

11. Boonchuwong P. Review and Analysis Method at Farm Level Fisheries Economic Division Department of Fisheries, 2000. - 184 p.

12. Павлов К. В. Интенсификация экономики в условиях неопределенности рыночной среды / К. В. Павлов. - М.: Магистр, 2007. - 272 c.

\section{References}

1. The state program "Development of agriculture and fish farming in the Belgorod region for 2014-2020" / ed. of the Decrees of the Government of the Belgorod Region of

Стаття надійшла

до редакції : 18.08 .2018 p.
24.02.2014 No. 55-pp, of 06/30/2014 № 235-pp, of 07/15/2014 № 258.

2. Federal Law of the Russian Federation dated July 2, 2013 N 148-FZ "On aquaculture (fish farming) and on amending certain legislative acts of the Russian Federation". Retrieved from: http://www.rg.ru/

3. Aquaculture development strategy in the Russian Federation for the period up to 2020 http://www.mcx.ru/

4. Review of aquaculture of Russia and the world in 2017. (2018). Information and analytical service of JSC "Development", Belgorod, 73.

5. Kulachenko, V. P. \& Kulachenko, I. V. \& Litvinov, Yu. N. (2011). Biological indicators and nutritional value of fish species in aquaculture of the Belgorod region. Bulletin of the Kursk State Agricultural Academy, 1, 53-55.

6. Zikova, N. V. (2010). Study of trends, patterns, factors and conditions for the development of aquaculture in the system of sustainable functioning of the regional economy. Russian Journal of Entrepreneurship, 12 Vol. 2 (174), 183-188.

7. Khmyrov, A. V. (2010). The project "Reproduction of fish species listed in the Red Book of the Belgorod Region". Belgorod Agromir, 6, 28-29.

8. Thirds of global food fish supply by 2030. Retrieved from: http://www.fao.org

9. Hillary, S. Egna \& Claude, E. (1997). Boyd Dynamics of Aquaculture / CRC Press. Retrieved from: http://insightmaker.com /

10. Joint FAO/NACA/WHO Study Group Food safety issues associated with products from aquaculture. (1999). World Health Organization Technical Report Series № 883. Retrieved from: http://www.who.int /

11. Boonchuwong, P. (2000). The Review of the Fisheries Economic Division, Department of Fisheries, 184.

12. Pavlov, K. V. (2007). Intensification of the economy in an uncertain market environment. Moscow: Master, 272.

\footnotetext{
Стаття прийнята

до друку: 20.11.2018 p.
}

Бібліографічний опис для цитування :

Павлов К. В. Современное состояние и перспективы развития аквакультуры: федеральный и региональный аспекты / К. В. Павлов, И. Г. Андреева, М. Г. Метелева // Часопис економічних реформ. - 2018. - № 4 (32). - С. 11-18. 